\title{
PENENTUAN KUALITAS BUAH PEPAYA CALIFORNIA MENGGUNAKAN
} METODE K-NN

\author{
Muhammad Ezar Al Rivan ${ }^{1 *}$, Molavi Arman ${ }^{2}$ Winston Kennedy ${ }^{3}$ \\ Program Studi Teknik Informatika, Universitas Multi Data Palembang, Palembang ${ }^{1,3}$ \\ Program Studi Manajemen Informatika, Universitas Multi Data Palembang, Palembang ${ }^{2}$ \\ e-mail: meedzhar@mdp.ac.id ${ }^{1}$, molavi.arman@mdp.ac.id ${ }^{2}$, winkenedy@ gmail.com³
}

\begin{abstract}
Abstrak
Pepaya merupakan salah satu buah tropis yang banyak manfaat. Penentuan kualitas buah pepaya secara konvensional memiliki keterbatasan. Penelitian ini dilakukan untuk menentukan kualitas pepaya berdasarkan bentuk fisiknya. Metode yang digunakan untuk menentukan kualitas buah pepaya yaitu dengan menggunakan metode k-Nearest Neighbors (k-NN). Metode k-NN digunakan untuk melakukan klasifikasi dengan cara mencari kedekatan data uji dengan basis data yang sudah diberi label. Ciri fisik papaya dapat dilihat dari warna, ukuran dan defect. RGB merupakan salah satu fitur warna. Namun fitur warna yang digunakan yaitu fitur R (Red) dan G (Green) sedangkan untuk fitur ukuran yaitu minor axis dan major axis. Penelitian ini menggunakan jarak Euclidean dan Manhattan dengan nilai $k=3,5,7$, dan 9. Citra buah pepaya yang digunakan dalam penelitian ini merupakan citra buah pepaya yang diambil sendiri yang terdiri dari baik, sedang, dan jelek dengan total sebanyak 150 citra yang terbagi menjadi 120 data training dan 30 data testing. Hasil terbaik yang diperoleh yaitu dengan menggunakan jarak Euclidean dan nilai k sebesar 7 dengan accuracy sebesar 86,67\%, precision sebesar 87,50\%, dan recall sebesar $80,00 \%$. Nilai accuracy, precision dan recall menunjukkan perfoma penentuan kualitas yang baik.
\end{abstract}

Kata kunci : Kualitas; Pepaya California; k-NN

\begin{abstract}
Papaya is a tropical fruit that has various benefit. Conventional determination of the quality of papaya fruit has limitations. The goal from this research is to determine quality of papaya based on physical. The method that used to determine papaya quality is $k$-Nearest Neighbor $(k-N N)$. Determining the quality of papaya fruit can of course be done using the $k$-NN (k-Nearest Neighbors). K-NN classify based on nearest point between data testing and labeled database. Papaya physic features showed by color, size and defect. RGB are one of color features. But color features used are $R(R e d)$ and $G$ (Green), otherwise size features are minor axis and major axis. This research uses Euclidean and Manhattan distances with values of $k=3,5$, 7, and 9. The papaya image used in this research is self collected which consists of good, medium, and poor with a total of 150. The image is divided into 120 training data and 30 testing data. The best result using Euclidean distance and $k$ value of 7 with an accuracy of $86.67 \%$, a precision of $87.50 \%$, and a recall of $80.00 \%$. This accuracy, precision and recall show good perform in determining papaya quality.
\end{abstract}

Keywords : Quality; California Papaya; K-NN 


\section{PENDAHULUAN}

Indonesia merupakan salah satu negara penghasil buah-buahan tropis, seperti pisang, nanas, pepaya, dan mangga terbesar di ASEAN [1]. Pepaya merupakan salah satu buah tropis yang mempunyai nilai ekonomi tinggi, sumber gizi, dan dapat tumbuh di setiap musim [2]. Penentuan kualitas dari pepaya masih dilakukan secara konvensional menggunakan visual mata manusia yang memiliki keterbatasan karena persepsi manusia yang berbeda dan tidak konsistennya manusia dalam menentukan kualitas buah karena mengalami kelelahan.

Perkembangan teknologi tentunya dapat dikembangkan untuk membantu melakukan penentuan kualitas suatu objek berdasarkan karakteristik yang dimiliki oleh objek tersebut. Pengolahan citra digital dapat digunakan untuk menganalisis ciri atau fitur yang terdapat pada citra. Fitur-fitur yang dapat dianalisis adalah warna, ukuran, dan defect area. Proses untuk menentukan kualitas dari suatu objek dapat dibantu dengan sistem yang dapat menentukan kualitas berdasarkan karakteristik yang dimilikinya.

Penelitian dalam penentuan kualitas buah telah dilakukan dengan menggunakan metode k-NN, seperti penelitian [2] menggunakan metode k-NN untuk klasifikasi tingkat kematangan buah pepaya, kemudian penelitian [3] menggunakan metode k-NN untuk klasifikasi mutu padi yang memperoleh akurasi sebesar $96.40 \%$. Penelitian lainnya juga dilakukan oleh [4] untuk klasifikasi mutu buah jambu biji memperoleh akurasi sebesar $91.25 \%$, dan penelitian [1] untuk klasifikasi mutu buah pepaya memperoleh akurasi sebesar 83,34\%. Penelitian [5] menggunakan metode Fuzzy Neural Network untuk identifikasi tingkat kemanisan buah belimbing dengan tingkat akurasi sebesar 100\%. Terdapat juga penelitian dengan menggunakan metode SVM yang dilakukan oleh [6] untuk klasifikasi level kematangan tomat memperoleh akurasi sebesar $77.84 \%$. Penelitian lainnya juga dilakukan oleh [7] untuk klasifikasi kematangan buah mengkudu memperoleh akurasi sebesar $87.22 \%$. Selain itu juga terdapat penelitian yang menggunakan Jaringan Saraf Tiruan (JST) yang dilakukan oleh [8] untuk klasifikasi mutu buah pepaya memperoleh akurasi sebesar $86.11 \%$.

Penelitian dalam penentuan kualitas buah telah dilakukan dengan menggunakan metode ekstraksi fitur LVQ oleh [9] untuk klasifikasi kualitas dari buah Garcinia mangostana L. dengan hasil yang baik. Kemudian terdapat penelitian yang menggunakan metode HSV yang dilakukan oleh [2] untuk tingkat kematangan buah pepaya memperoleh akurasi sebesar $83,34 \%$. Lalu terdapat penelitian [5] yang menggunakan fitur warna RGB untuk identifikasi tingkat manis buah belimbing dengan tingkat akurasi sebesar $100 \%$, kemudian penelitian [6] untuk klasifikasi level kematangan buah tomat memperoleh akurasi sebesar $77.84 \%$. Lalu ada penelitian yang menggunakan fitur warna dan tekstur yang dilakukan oleh [7] untuk klasifikasi kematangan buah mengkudu memperoleh akurasi sebesar $87.22 \%$, lalu penelitian yang dilakukan [4] untuk klasifikasi mutu buah jambu biji memperoleh akurasi sebesar $91.25 \%$. Selain itu juga terdapat penelitian yang menggunakan metode GLCM yang dilakukan oleh [8] untuk pendugaan kelas mutu buah pepaya memperoleh akurasi sebesar $86.11 \%$. Penelitian lain dilakukan oleh [10] yang melakukan penentuan mutu buah pepaya dengan menggunakan FuzzyTsukamoto memperoleh akurasi sebesar 90\%. Penelitian lain dilakukan oleh [11] untuk penentuan mutu buah pepaya dengan metode Fuzzy-Mamdani memperoleh akurasi sebesar $75 \%$. Pada penelitian yang dilakukan [12] untuk menentukan kualitas papaya menggunakan jaringan saraf tiruan 
yang memberikan hasil $82,6 \%$ dengan menggunakan training function trainrp.

Berdasarkan penelitian yang telah dilakukan, penggunaan metode k-NN banyak digunakan untuk klasifikasi dan penentuan mutu dari buah, salah satunya pepaya. Metode k-NN dapat mengatasi data campuran berupa polinomial dan numerik [3] dengan menggunakan fitur warna RGB, dimana hanya digunakan fitur $R$ dan $G$ karena kualitas dari buah pepaya dinilai berdasarkan warna merah dan hijau yang terlihat, dan defect area, serta penggunaan dari major axis dan minor axis, diharapkan penentuan kualitas dari buah pepaya sendiri dapat memiliki hasil yang baik pula. Penelitian ini menggunakan parameter pengujian accuracy, precision, dan recall.

\section{TINJAUAN PUSTAKA}

\subsection{Pepaya}

Indonesia merupakan salah satu negara penghasil buah-buahan tropis, seperti pisang, nanas, pepaya, dan mangga terbesar di ASEAN [2]. Pepaya merupakan salah satu buah tropis yang mempunyai nilai ekonomi tinggi, sumber gizi, dan dapat tumbuh di setiap musim [2]. Penentuan kualitas dari pepaya masih dilakukan secara konvensional menggunakan visual mata manusia yang memiliki keterbatasan karena persepsi manusia yang berbeda dan tidak konsistennya manusia dalam menentukan kualitas buah karena mengalami kelelahan.

\section{2 k-NN (k-Nearest Neighbors)}

k-NN merupakan metode klasifikasi yang menentukan kategori berdasarkan mayoritas kategori pada k-tetangga terdekat [13][14][15]. Klasifikasi dilakukan berdasarkan objek-objek latih terdekat dari sebuah objek uji. k-NN dapat mengatasi data campuran berupa polinomial dan numerik [3][3]. Tahapan-tahapan proses klasifikasi dari k-NN adalah sebagai berikut [13][14][15].

1. Menentukan nilai $\mathrm{k}$.

2. Menghitung jarak antara data yang diuji dengan semua data latih.
3. Mengurutkan perhitungan jarak antara data uji dengan semua data latih berdasarkan jarak terkecil.

4. Membentuk kelompok berdasarkan nilai dengan nilai jarak.

5. Pilih nilai (kelas) dengan kemunculan paling sering.

Penghitungan jarak Manhattan dan jarak Euclidean dilakukan dengan menggunakan Persamaan (1) [16] dan Persamaan (2) [17] sebagai berikut,

$$
\begin{aligned}
& d_{i j}=\sum W\left|x_{i}-c_{j}\right| \\
& d\left(x_{i}, x_{j}\right)=\sqrt{\sum_{r=1}^{n}\left(a_{r}\left(x_{i}\right)-a_{r}\left(x_{j}\right)\right)^{2}}
\end{aligned}
$$

Dimana $d_{i j}$ adalah jarak Manhattan antara $\mathrm{i}$ dan $\mathrm{j}, \mathrm{W}$ adalah jumlah bobot, $\mathrm{x}_{\mathrm{ik}}$ adalah nilai baru, dan $c_{\mathrm{jk}}$ adalah nilai yang sudah ada. Lalu d(xi, xj) adalah jarak Euclidean, a adalah nilai bobot, dan $\mathrm{x}$ adalah nilai pada indeks $\mathrm{i}$ atau $\mathrm{j}$.

Cara kerja metode k-NN bekerja adalah dengan mengukur kedekatan antara objek baru dengan objek lama untuk menentukan termasuk kelas mana objek baru tersebut [18]. k-NN relatif tidak sensitif terhadap error dalam dataset dan dapat digunakan untuk memproses dataset berukuran besar [19].

\subsection{RGB (Red Green Blue)}

RGB merupakan salah satu fitur warna yang dapat diperoleh dari suatu citra. Pada setiap citra warna, masing-masing blue memiliki warna tertentu, yaitu warna merah (Red), hijau (Green), dan biru (Blue). Nilai tersebut merupakan nilai dari setiap blue citra yang termasuk dalam segmentasi, sehingga hanya didapat nilai dari objek dari citra tersebut tanpa mengambil nilai blue pada background. Setiap blue citra memiliki komponen warna RGB dengan panjang 8 bit yang disimpan dalam tabel RGB. Masingmasing warna memiliki range 0 - 255, sehingga totalnya adalah $255^{3}=16.581 .375$ $(16 \mathrm{~K})$ variasi warna berbeda pada citra, dimana variasi warna ini cukup untuk citra.

\subsection{Minor Axis dan Major Axis}

Setiap objek memiliki major axis dan minor axis [20]. Minor axis merupakan jarak terpendek centroid dengan boundary objek. 
Major axis merupakan jarak terpanjang centroid dengan boundary objek [21].

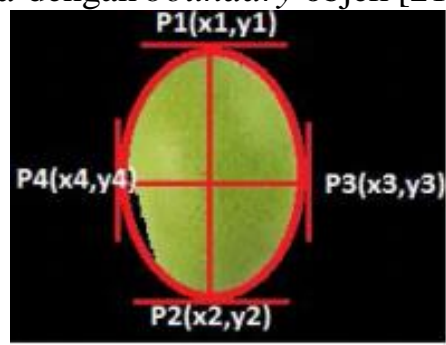

Sumber : R. Pandey et al [22]

Gambar 1. Minor axis dan major axis

Mendapatkan minor dan major axis, pada citra objeknya dideteksi dan diukur lebar dan panjang dari objek yang telah terdeteksi. Mayor axis adalah panjang dari objek dan minor axis adalah lebar dari objek [11]. Mayor axis dan minor axis digunakan untuk mendapatkan ukuran objek dalam satuan blue [11] yang dapat dihitung dengan menggunakan Persamaan (3) dan Persamaan (4) dimana nilai $x$ dan y merupakan letak titik P sebagai berikut [22].

$2 \alpha=$

$\sqrt{\sum_{r=1}^{n}\left(x_{2}-x_{1}\right)^{2}+\left(y_{2}-y_{1}\right)^{2}}$

$2 \beta=$

$$
\sqrt{\sum_{r=1}^{n}\left(x_{4}-x_{3}\right)^{2}+\left(y_{4}-y_{3}\right)^{2}}
$$

Dimana $2 \alpha$ adalah nilai dari major axis, $2 \beta$ adalah nilai dari minor axis, dan $\mathrm{x}$ dan y merupakan kordinat titik pada sumbu $\mathrm{x}$ dan sumbu $\mathrm{y}$.

\subsection{Defect Area}

Defect area merupakan metode untuk mendapatkan defect (kecacatan) dari suatu objek pada citra. Pada proses deteksi kecacatan (defect detection), citra diubah menjadi citra grayscale terlebih dahulu. Citra yang dihasilkan pada proses ini berupa citra biner yang menunjukkan area kecacatan dan luas kecacatan.

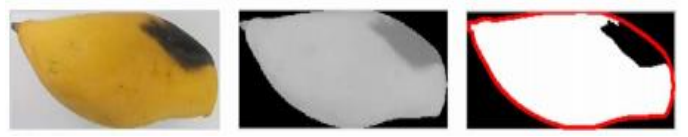

Sumber : R. Pandey et al [22]

Gambar 2. Defect area

Mendapatkan defect area, citra objek diubah menjadi citra grayscale, lalu objeknya dideteksi dan dilihat kecacatan (defect area) yang ada pada objek yang telah terdeteksi. Defect area diukur dalam persentase dengan mengambil rasio wilayah objek yang terinfeksi terhadap citra biner wilayah objek yang dapat dapat dilihat pada Persamaan (5) sebagai berikut [11].

Defect Area $(\%)=\frac{\text { white }}{\text { white }+ \text { black }} \times$

$100 \%$

\section{METODOLOGI PENELITIAN}

Metodologi penelitian merupakan uraian tentang metode metode yang digunakan dalam penelitian.

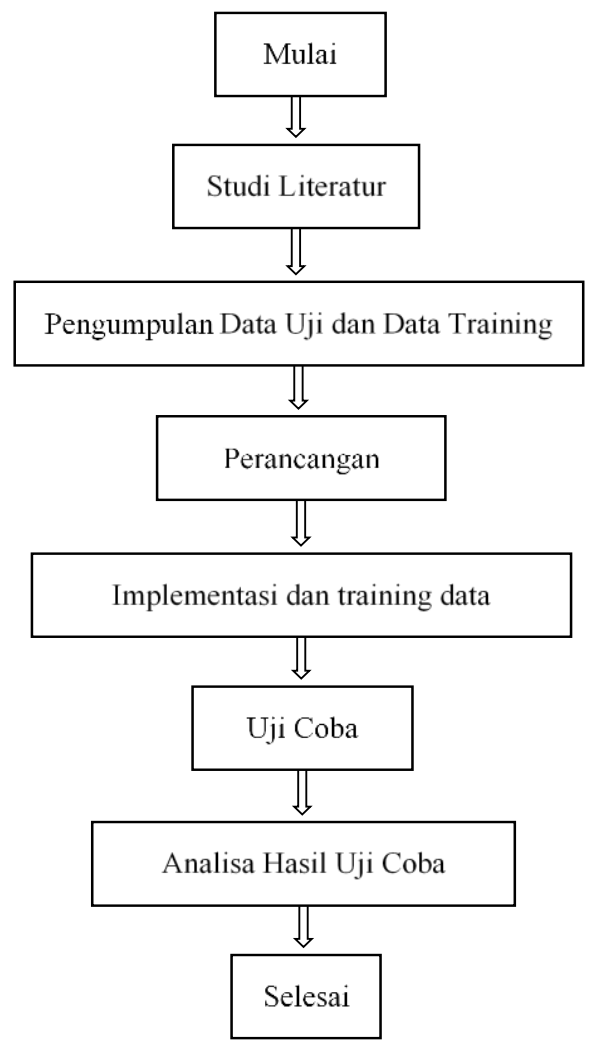

Gambar 3. Metodologi Penelitian Sumber : Hasil Penelitian

1. Studi Literatur

Pada tahap ini dilakukan pembelajaran literatur berupa jurnal dan buku yang berkaitan dengan topik penelitian ini, yaitu penggunaan metode $\mathrm{k}-\mathrm{NN}$ dan penelitian terkait kualitas dan mutu dari objek yang dalam penelitian ini adalah buah, dengan menggunakan faktor berupa warna dan tekstur dari objek tersebut. Fitur yang akan digunakan adalah R, G. minor axis, major axis, dan defect area tanpa varianvariannya. 
2. Pengumpulan Data Uji dan Data Training

Pada tahap ini dilakukan pengumpulan data training yang berupa dataset gambar dari setiap jenis kualitas buah pepaya. Dataset yang diolah merupakan citra buah pepaya yang diambil langsung pada saat penelitian dilakukan. Dataset buah pepaya yang digunakan terdiri dari 150 citra dengan format *JPG. Dataset terbagi menjadi bagus, sedang, dan jelek, pada setiap jenis terdapat 50 gambar.

3. Perancangan

Pada tahap ini dilakukan perancangan penelitian dan sistem yang dibutuhkan untuk melakukan penelitian ini, yaitu penggunaan metode k-NN.

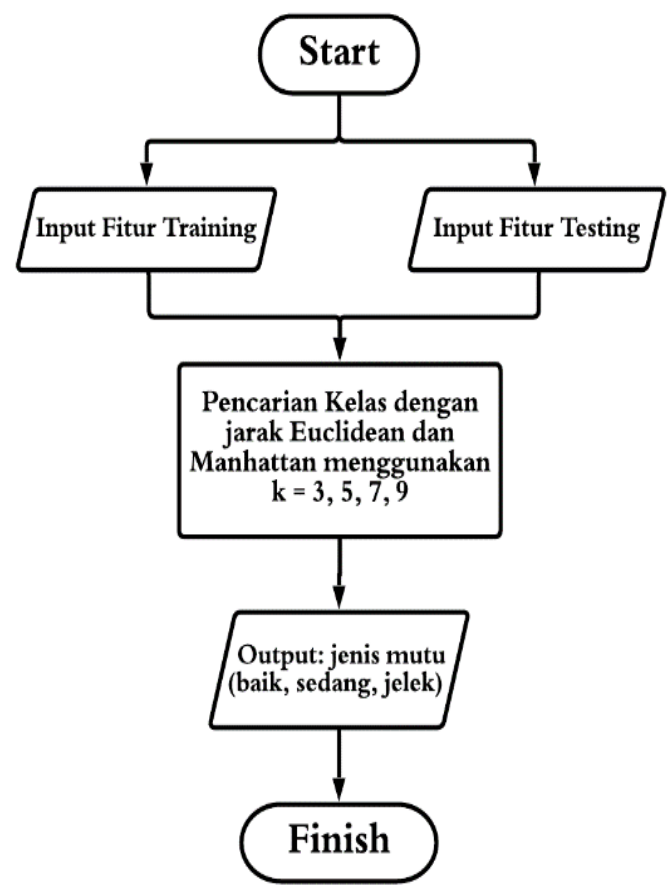

Sumber : Hasil Penelitian

Gambar 4. Penggunaan Metode k-NN

Penentuan kualitas buah pepaya tersebut akan menggunakan faktor berupa warna, ukuran, dan kecacatan. Citra diambil untuk diekstraksi fitur warna, ukuran, dan kecacatan. Fitur yang akan digunakan adalah R, G. minor axis, major axis, dan defect area. Sistem akan melakukan pembagian dataset menjadi data training dan data testing. Dari data training dan data testing akan dilakukan ekstraksi fitur R, G, Major Axis, Minor Axis, dan Defect area yang akan digabungkan sebagai Data Fitur. Kemudian dilakukan penentuan jenis mutu dengan menghitung jarak Euclidean atau jarak Manhattan dengan menggunakan variasi nilai k sebesar 3, 5, 7, dan 9. Dari setiap data testing, akan diperoleh hasil (output) berupa kualitas dari buah pepaya tersebut.

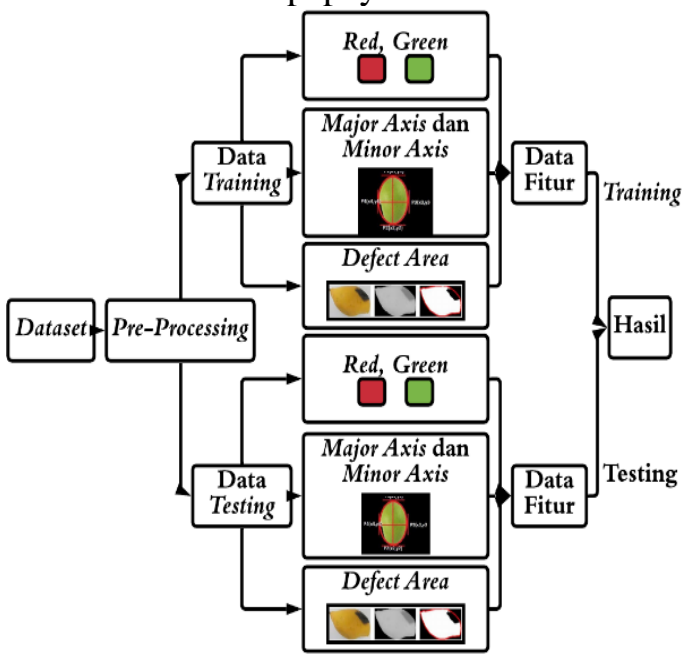

Sumber : Hasil Penelitian

Gambar 5. Rancangan Sistem

4. Implementasi dan Training Data

Pada tahap ini dilakukan implementasi dari penelitian dan sistem yang telah dirancang sebelumnya dan training dari data-data training yang telah dikumpulkan sebelumnya agar sistem dapat mengenali dan dapat melakukan klasifikasi terhadap data uji yang telah dikumpulkan sebelumnya. Pada tahapan ini dilakukan pelatihan (training) pada sistem agar dapat melakukan penentuan kualitas buah pepaya California dengan menggunakan metode kNN dengan fitur R, G. minor axis, major axis, dan defect area tanpa varian-variannya.

5. Uji Coba

Pada tahap ini dilakukan uji coba terhadap data uji yang telah dikumpulkan sebelumnya dengan menggunakan sistem yang telah diimplementasi. Pada tahapan ini dilakukan pengujian dari sistem dalam melakukan penentuan kualitas dan hasil dari pengujian tersebut yang akan dicatat untuk dilakukan analisa setelah semua pengujian selesai.

6. Analisis Hasil Uji Coba

Pada tahap ini dilakukan analisis terhadap hasil uji coba yang telah dilakukan sebelumnya untuk menjawab tujuan dari penelitian ini. Hasil uji coba tersebut dihitung untuk mendapatkan tingkat 
keberhasilan dari metode yang digunakan dengan Confusion Matrix.

\begin{tabular}{|c|c|c|}
\hline \multicolumn{3}{|c|}{ Predicted Class } \\
\hline & $\mathrm{P}$ & $\mathrm{N}$ \\
\hline $\begin{array}{l}\text { Actual } \\
\text { Class }\end{array}$ & $\begin{array}{l}\text { True } \\
\text { Positives } \\
\text { (TP) }\end{array}$ & $\begin{array}{l}\text { False } \\
\text { Negatives } \\
(\mathrm{FN})\end{array}$ \\
\hline Class & \begin{tabular}{|l} 
False \\
Positives \\
(FP)
\end{tabular} & \begin{tabular}{|l} 
True \\
Negatives \\
$(\mathrm{TN})$
\end{tabular} \\
\hline
\end{tabular}

Sumber : Hasil Penelitian

Gambar 6. Confusion Matrix

Nilai yang didapat dari Confusion Matrix yang digunakan dalam mengukur keberhasilan dari penelitian ini adalah precision, recall, dan accuracy yang dapat dihitung dengan menggunakan Persamaan (6), (7), dan (8).

$$
\begin{aligned}
& \text { precision }=\frac{T P}{T P+F P} \\
& \text { recall }=\frac{T P}{T P+F N} \\
& \text { accuracy }=\frac{T P+T N}{T P+T N+F P+F N}
\end{aligned}
$$

Dimana TP (True Positive) adalah jumlah data yang diprediksi dengan benar, FP (False Positive) adalah jumlah dta yang diprediksi kurang tepat sebagai kelas tersebut, FN (False Negative) adalah jumlah dari data yang diprediksi sebagai kelas lain, dan TN (True Negati) adalah jumlah dari data yang diprediksi sebagai kelas lain dan bukan kelas tersebut. Dari analisa inilah akan ditarik kesimpulan mengenai seberapa penggunaan metode $\mathrm{k}-\mathrm{NN}$ dalam penentuan kualitas buah pepaya California.

\section{HASIL DAN PEMBAHASAN}

Pada penelitian ini telah dilakukan pengujian menggunakan metode $\mathrm{k}-\mathrm{NN}$ dengan fitur R, G. minor axis, major axis, dan defect area menggunakan jarak Euclidean dan Manhattan dan nilai k sebesar 3, 5, 7, dan 9 dengan hasil sebagai berikut.

Tabel 1. Hasil dengan Jarak Euclidean

\begin{tabular}{|l|l|l|l|}
\hline $\mathrm{k}$ & Accuracy & Precision & Recall \\
\hline 3 & $86,67 \%$ & $80,59 \%$ & $80,00 \%$ \\
\hline 5 & $82,22 \%$ & $75,04 \%$ & $73,33 \%$ \\
\hline 7 & $86,67 \%$ & $87,50 \%$ & $80,00 \%$ \\
\hline 9 & $80,00 \%$ & $72,26 \%$ & $70,00 \%$ \\
\hline
\end{tabular}

Sumber : Hasil Penelitian
Tabel 2. Hasil dengan Jarak Manhattan

\begin{tabular}{|l|l|l|l|}
\hline $\mathrm{k}$ & Accuracy & Precision & Recall \\
\hline 3 & $84,44 \%$ & $76,11 \%$ & $76,67 \%$ \\
\hline 5 & $86,67 \%$ & $81,48 \%$ & $80,00 \%$ \\
\hline 7 & $82,22 \%$ & $80,65 \%$ & $73,33 \%$ \\
\hline 9 & $82,22 \%$ & $78,31 \%$ & $73,33 \%$ \\
\hline
\end{tabular}

Sumber : Hasil Penelitian

Dapat dilihat bahwa accuracy terbaik didapat dengan menggunakan nilai k sebesar 3 dan 7 untuk jarak Euclidean dan nilai $\mathrm{k}$ sebesar 5 untuk jarak Manhattan dengan accuracy sebesar $86,67 \%$, precision terbaik didapat dengan menggunakan nilai k sebesar 7 untuk jarak Euclidean dengan precision sebesar $87,50 \%$, dan recall terbaik didapat dengan menggunakan nilai $\mathrm{k}$ sebesar 3 dan 7 untuk jarak Euclidean dan nilai k sebesar 5 untuk jarak Manhattan dengan recall sebesar $80,00 \%$. Pada tabel tersebut juga dapat dilihat bahwa perubahan nilai $\mathrm{k}$ dan variasi jarak mempengaruhi nilai dari accuracy, precision, dan recall walaupun tidak terlalu signifikan. Sehingga pada penggunaan dataset ini dengan menggunakan metode k$\mathrm{NN}$ dengan fitur R, G. minor axis, major axis, dan defect area dengan jarak Euclidean dan Manhattan dan perubahan nilai $k$ mempengaruhi nilai accuracy, precision, dan recall.

\section{KESIMPULAN}

Berdasarkan hasil yang didapat dalam penelitian ini, dapat ditarik kesimpulan bahwa penggunaan variasi jarak dan nilai $\mathrm{k}$ pada metode k-NN dengan fitur R, G. minor axis, major axis, dan defect area terbaik dalam menentukan kualitas dari buah pepaya California didapat dengan menggunakan jarak Euclidean dan nilai k sebesar 7 dengan accuracy sebesar $86,67 \%$, precision sebesar $87,50 \%$, dan recall sebesar $80,00 \%$.

\section{SARAN}

Berdasarkan penelitian yang telah dilakukan, terdapat beberapa saran yang dapat dilakukan pada penelitian selanjutnya antara lain adalah sebagai berikut: 
1. Penggunaan metode ekstraksi fitur lain untuk mendapat performa yang lebih baik.

2. Penambahan jumlah data yang digunakan dalam penelitian.

3. Penggunaan data testing yang lebih beragam untuk menguji performa sesungguhnya dari metode k-NN dengan fitur R, G. minor axis, major axis, dan defect area.

\section{DAFTAR PUSTAKA}

[1] F. Wibowo and A. Harjoko, "Klasifikasi Mutu Pepaya Berdasarkan Ciri Tekstur GLCM Menggunakan Jaringan Saraf Tiruan," Khazanah Inform. J. Ilmu Komput. dan Inform., vol. 3, no. 2, p. 100, 2018, doi: 10.23917/khif.v3i2.4516.

[2] F. Wibowo, D. Hakim, and S. Sugiyanto, "PENDUGAAN KELAS MUTU BUAH PEPAYA BERDASARKAN CIRI TEKSTUR GLCM MENGGUNAKAN ALGORITMA K-NEAREST NEIGHBORS," J. Nas. Pendidik. Tek. Inform. JANAPATI, vol. 7, no. 1, pp. 100-106, 2018.

[3] W. J. Shudiq, "Penerapan K-Nearest Neighbor Berbasis Algoritma Genetika Untuk Klasifikasi Mutu Padi Organik," in Prosiding SNATIF, 2017, vol. 4, no. 1, pp. 121-126.

[4] T. Y. Prahudaya and A. Harjoko, "METODE KLASIFIKASI MUTU JAMBU BIJI MENGGUNAKAN KNN BERDASARKAN FITUR WARNA DAN TEKSTUR," $J$. Teknosains, vol. 6, no. 2, p. 113, Aug. 2017, doi: 10.22146/teknosains.26972.

[5] R. N. Whidhiasih, "Identifikasi tingkat manis buah belimbing berdasarkan citra red green blue menggunakan fuzzy neural network," PIKSEL Penelit. Ilmu Komput. Sist. Embed. Log., vol. 3, no. 2, pp. 109-120, 2015.

[6] N. Astrianda, "Klasifikasi Kematangan Buah Tomat Dengan Variasi Model Warna Menggunakan
Support Vector Machine," VOCATECH Vocat. Educ. Technol. J., vol. 1, no. 2, pp. 45-52, Apr. 2020, doi: 10.38038/vocatech.v1i2.27.

[7] S. F. Kusuma, R. E. Pawening, and R. Dijaya, "Otomatisasi klasifikasi kematangan buah mengkudu berdasarkan warna dan tekstur," Regist. J. Ilm. Teknol. Sist. Inf., vol. 3, no. 1, p. 17, 2017, doi: 10.26594/r.v3i1.576.

[8] F. Wibowo and A. Harjoko, "Klasifikasi Mutu Pepaya Berdasarkan Ciri Tekstur GLCM Menggunakan Jaringan Saraf Tiruan," Khazanah Inform. J. Ilmu Komput. dan Inform., vol. 3, no. 2, p. 100, Jan. 2018, doi: 10.23917/khif.v3i2.4516.

[9] E. Permata and A. Suherman, "Klasifikasi Kualitas Buah Garcinia Mangostana L. Menggunakan Metode Learning Vector Quantization," Semin. Nas. Teknol. Inf. dan Komun., vol. 2015, no. March, p. 425, 2015.

[10] M. E. Al Rivan and J. Suherman, "Penentuan Mutu Buah Pepaya California (Carica Papaya L.) Menggunakan Fuzzy Mamdani," Elkha, vol. 12, no. 2, p. 76, 2020, doi: 10.26418/elkha.v12i2.41164.

[11] M. E. Al Rivan, A. Octavia, and I. Wijaya, "DESAIN MODEL FUZZY-TSUKAMOTO UNTUK PENENTUAN KUALITAS BUAH PEPAYA CALIFORNIA (CARICA PAPAYA L.) BERDASARKAN BENTUK FISIK," J. SAINTEKOM, vol. 11, no. 1, 2021, doi: 10.33020/saintekom.v11i1.155.

[12] M. E. Al Rivan and G. R. Sung, "Identifikasi Mutu Buah Pepaya California ( Carica Papaya L .) Menggunakan Metode Jaringan Syaraf Tiruan," vol. 10, pp. 113-119, 2021.

[13] G. I. Sebastian, Y. A. Sari, and R. C. Wihandika, "Algoritme K-Nearest Neighbors Untuk Klasifikasi Jenis Makanan Dari Citra Digital Dengan Local Binary Patterns Dan Color Moments," J. Pengemb. Teknol. Inf. 
dan Ilmu Komput., vol. 3, no. 7, pp. 6473-6479, 2019, [Online]. Available: http://jptiik.ub.ac.id/index.php/jptiik/article/view/5730.

[14] M. E. Al Rivan and Y. Yohannes, "Klasifikasi Mamalia Berdasarkan Bentuk Wajah Dengan k-NN Menggunakan Fitur CAS dan HOG," JATISI (Jurnal Tek. Inform. dan Sist. Informasi), vol. 5, no. 2, pp. 169176, 2019, doi: 10.35957/jatisi.v5i2.139.

[15] M. E. Al Rivan, H. Irsyad, A. T. Narta, and K. Kevin, "Pengenalan Alfabet American Sign Language Menggunakan K-Nearest Neighbors dengan Ekstraksi Fitur Histogram of Oriented Gradients," vol. 5, pp. 328339, 2019.

[16] K. Latifah, "Kombinasi Algorithma K-NN dan Manhattan Distance untuk Menentukan Pemenang Lelang," $J$. Inform. Upgris, pp. 49-58, 2015, [Online]. Available: https://docplayer.info/34038947Kombinasi-algorithma-k-nn-danmanhattan-distance-untukmenentukan-pemenang-lelang.html.

[17] Z. Zhai, H. Jiang, L. L, and Y. Liu, "Adaptive truncation coding for computed tomography images," in Information Technology, 1st Editio., Y. Wan, L. Shao, L. Wang, and J. Sun, Eds. CRC Press, 2015.

[18] F. Gorunescu, Data Mining Concept Model and Techniques. 2011.

[19] G. J. Myatt, Making Sense of Data A Practical Guide to Exploratory Data Analysis and Data Mining. New Jersey: John Wiley \& Sons, Inc, 2007.

[20] O. Soesanto, A. Yusuf, D. H. Mursyidin, and M. S. Pebriadi, "Jaringan Saraf Radial Basis Probabilistic untuk Identifikasi Morfologi Benih Padi Rawa Kalimantan Selatan," J. Ilmu Komput. dan Agri-Informatika, vol. 4, no. 1, p. 14, Jan. 2017, doi: 10.29244/jika.4.1.14-21.

[21] I. Muhimmah, N. Lusiyana, R. E. Listanto, and R. A. Nugraheni,
"PURWARUPA

SISTEM

IDENTIFIKASI

NYAMUK

BERDASARKAN

CITRA

MIKROSKOPIS

DIGITAL,"

Teknoin, vol. 22, no. 11, pp. 77-85,

Nov. 2016, doi:

10.20885/teknoin.vol22.iss11.art4.

[22] R. Pandey, N. Gamit, and S. Naik, "A novel non-destructive grading method for Mango (Mangifera Indica L.) using fuzzy expert system," in 2014 International Conference on Advances in Computing, Communications and Informatics (ICACCI), 2014, pp. 1087-1094, doi: 10.1109/ICACCI.2014.6968366. 